DOMESTIC AND OUTBOUND TOURISM DEMAND IN AUSTRALIA:

\title{
A System-of-Equations Approach
}

\section{George Athanasopoulos ${ }^{1}$, Minfeng Deng ${ }^{1}$, Gang $\mathrm{Li}^{2}$ and Haiyan Song ${ }^{3}$}

${ }^{1}$ Department of Econometrics and Business Statistics, Monash University, Clayton, VIC 3800, Australia

Emails: george.athanasopoulos@monash.edu (G. Athanasopoulos) minfeng.deng@monash.edu (M. Deng)

${ }^{2}$ School of Hospitality and Tourism Management, University of Surrey, Guildford, GU2 7XH, UK Email: g.li@surrey.ac.uk Telephone: +44 1483686356

Fax: +44 1483689511

${ }^{3}$ School of Hotel and Tourism Management, The Hong Kong Polytechnic University, Hong Kong Email: haiyan.song@polyu.edu.hk

\section{Research Highlights}

- $\quad$ Substitution relationships between Australian domestic and outbound tourism are found

- A dynamic almost ideal demand system model is employed

- $\quad$ Long-run and short-run demand elasticities are calculated

- A new price variable based on purchasing power parity index is developed

- $\quad$ Further promotion of Australian domestic tourism is recommended

The paper should be cited as follows:

Athanasopoulos G, Deng M, Li G, Song H. (2014) 'Modelling substitution between domestic and outbound tourism in Australia: A system-of-equations approach'. Tourism Management, 45, pp. 159170. doi: $10.1016 /$ j.tourman.2014.03.018 


\title{
DOMESTIC AND OUTBOUND TOURISM DEMAND IN AUSTRALIA:
}

\section{A System-of-Equations Approach}

\begin{abstract}
This study uses a system-of-equations approach to model the substitution relationship between Australian domestic and outbound tourism demand. A new price variable based on relative ratios of purchasing power parity index is developed for the substitution analysis. Both long-run and short-run demand elasticities are calculated based on the estimated almost ideal demand systems. The empirical results reveal significant substitution relationships between Australian domestic tourism and outbound travel to Asia, the UK and the US. This study provides scientific support for necessary policy considerations to promote domestic tourism further.
\end{abstract}

Key words: domestic tourism, substitution, almost ideal demand system, purchasing power parity, Australia 


\section{INTRODUCTION}

In a recent report by Tourism Research Australia in June, 2011, a widening tourism trade deficit (calculated as the difference between total inbound revenue and total outbound expenditure) has been identified. A peak surplus of \$AU 3.6 billion in 1999-2000 has turned into a deficit of \$AU 5 billion in 2009-2010 (Tourism Research Australia, 2011a). The high value of the Australian dollar was said to be one of the key factors in contributing to the deficit.

For the financial year ending June 2011 international inbound tourism consumption was estimated to be \$AU23.6 billion while domestic consumption was estimated at \$AU71.9 billion, three times the size of the international inbound market. The consumption of Australian residents overseas was estimated to be \$AU37.9 (Australian Bureau of Statistics, 2011). Figure 1 shows an average growth of outbound tourism consumption as a percentage of household final consumption expenditure of approximately $4 \%$ per annum over the period 2003-2011, in contrast to an average decline of approximately $3 \%$ per year for domestic tourism.

"The greatest impact of the high Australian dollar on the Australian industry is the increasing number of Australians able to afford, and choosing, to travel overseas ... this represents a significant challenge for the industry" (Tourism Australia, May 2011).

\section{\{Insert Figure 1 about here $\}$}

An initial warning of the decline in demand for the domestic market was first issued by Athanasopoulos and Hyndman (2008). Since then a few other academic studies have followed on the domestic market (see for example Allen, Yap, \& Shareef, 2009, Divisekera, 2010, Deng \& Athanasopoulos, 2011, Yap \& Allen, 2011). However, despite the common belief among Australian tourism stakeholders, as expressed by the above quote, no study (academic or otherwise) to date has attempted to explicitly model and quantify the possible substitution between domestic and outbound tourism demand. This study therefore aims to fill the gap in the literature by investigating the potential substitution relationship between Australians' demand for domestic tourism and for international outbound tourism, based on a theoretically sound system-of-equations model: the almost ideal demand system (AIDS) model.

\section{LITERATURE REVIEW}

In the tourism economics literature, demand for international tourism has attracted predominant research interests, while little attention has been paid to the demand for 
domestic tourism. For example, in a review article Li, Song, and Witt (2005) identified 80 empirical studies on econometric modelling and forecasting of international tourism demand published between 1980 and 2004. Song and Li (2008) further reviewed 121 econometric and time-series analyses of international tourism demand during the period 2000-2007. However, very few publications are found to exclusively focus on domestic tourism demand. The exceptions include Kim and Ngo (2001), Pyo, Uysal, and McLellan (1991), and Witt, Newbould, and Watkins (1992). More recently, some research attention has been paid particularly to the Australian domestic tourism market. For example, Huybers (2003) applied the discrete choice modelling method to investigate the determining factors underlying the short-break holiday destination choices of Melbourne residents. Athanasopoulos and Hyndman (2008) used innovations state space models to forecast the domestic tourism demand. Allen, Yap and Shareef (2009) investigated the short-run and long-run causal relationships between economic factors and interstate tourism demand. Divisekera (2010) applied the AIDS model to analyse the demand for different tourism products distinguished by the motives of leisure and non-leisure tourism. Yap and Allen (2011) explored alternative leading indicators influencing domestic tourism demand. Despite some increasing interests in domestic tourism analysis, overall the tourism demand literature is still dominated by international tourism demand analysis. The reasons are related to international tourism's greater visibility and economic significance, as well as better data availability and quality (Pearce, 1987, Stabler, Papatheodorou, \& Sinclair, 2010).

\subsection{Substitution between International Tourism and Domestic Tourism}

International tourism is regarded as a special sort of international trade, and its economic significance is often discussed in relation to national balance of payments accounts. Inbound tourism is regarded as an export, an injection to the national economic output, recorded as a credit in the current account. On the contrary, outbound tourism is viewed as an import, which is a leakage of a national economy and appears as a debit entry into the current account (Seetaram, 2012, Smeral \& Witt, 1996, Tribe, 2011). Therefore, a higher level of tourism receipts from inbound tourists, along with a lower level of tourism expenditure by outbound tourists, would contribute to the improvement of a country's balance of payments (Baretje, 1982, Sugiyarto, Blake, \& Sinclair, 2003). On the other hand, faster growing outbound tourism than inbound tourism would lead to greater balance of payments deficit, as we have seen from the Australian case.

With respect to the demand for domestic tourism, it forms the "proving grounds" for the tourism industry and contributes significantly to a destination's tourism competitiveness. As Crouch \& Ritchie (1999, p. 141) noted, "a high domestic demand confers static efficiencies and encourages improvement and innovation.... Foreign demand thrives more readily when domestic tourism is well established." In many tourist destinations, domestic tourism contributes much more to the revenue of the tourism industry than inbound tourism does. For example, Australian domestic tourist expenditure has generally been four to five times 
higher than the inbound tourist spending (Huybers, 2003). Although the ratio dropped to three times in 2011, the dominance of domestic tourism is still clearly evident. In the context of Turkey, Seckelmann (2002) argued that promoting domestic tourism is more suitable for enhancing social sustainability and strengthening a more balanced regional development, because "domestic tourism does not carry all of the problems linked to international mass tourism such as external investment, outflow of the income, seasonal migration, overcommercialization of culture etc." (2002, p. 91).

The relationships between domestic tourism and international outbound tourism have also been discussed in the tourism literature. For example, Pearce (1989) stressed that substitution was a major policy issue that arose from this discussion. Given the nature of outbound tourism in balance of payments accounts, a destination government attempts to encourage more domestic tourism in substitution of outbound tourism. As noted by Ashworth and Johnson (1990, p. 13), "import substitution policies may be devised to retain more of such expenditure within the country's boundaries and thereby to raise indigenous employment." Similarly, Ashworth and Bergsma (1987) pointed out that governments tended to develop tourism policies to boost domestic tourism and reduce the outflow of foreign exchange.

The substitution between domestic and international outbound tourism can be further explained by the microeconomic foundation of tourism demand. A prospective tourist processes a utility function and follows a multiple-stage decision making process to reach a final decision which maximizes his/her utility, given the budget constraint he/she faces. At the first stage, the individual decides on travelling or not, facing the constraints of both time and budget. He/she needs to make a trade-off between unpaid leisure and paid work, because of the opportunity cost of leisure (Tribe, 2011). Meanwhile, he/she is constrained by available income to be allocated between leisure and tourism on one hand and other products on the other hand. The decision depends on the marginal rate of substitution between tourism and non-tourism consumption with the aim to achieve the highest utility overall (Eugenion-Martin \& Campos-Soria, 2011). At the second stage, with the allocated budget on tourism, the individual decides on the optimal allocation of the tourism budget between domestic and international tourism. The allocated share combination is subject to the change of relative price between domestic and international tourism. If international tourism becomes relatively cheaper, the individual is better off in real terms and may spend some or all of the increase in real income on international tourism (i.e., income effect). Meanwhile, the individual may spend more on the relatively cheaper international tourism and less on the more expensive domestic tourism (substitution effect). The optimal decision depends on the individual's preference and the marginal utility of prices (Stabler et al., 2010). Thus, facing the budget constraint and an aim to maximize the utility, substitution takes place between domestic and outbound tourism once the relative price (or real income) changes. 
Although the substitutability between domestic and outbound tourism is well accepted, most empirical studies on international tourism demand focused mainly on the substitution (as well as complementarity) among alternative international destinations, and domestic tourism was not included in the analysis explicitly (Crouch, 1996, Li et al., 2005). The substitution between domestic tourism and outbound tourism was considered in an implicit way by specifying a relative price variable - the destination's price level against the domestic price level of the origin country, adjusted by relevant exchange rates (e.g., Seetaram, 2012, Smeral \& Witt, 1996). In such a way the substitutability of domestic tourism for international tourism is assumed to exist rather than to be verified.

A number of studies have explicitly explored the distinction between domestic and outbound tourism, for instance, Eugenion-Martin \& Campos-Soria (2011), Nicolau \& Más (2005), van Soest \& Kooreman (1987). In these studies, survey data at the individual tourist level was used, and a multiple-stage decision making process was assumed. Domestic tourism and outbound tourism were explicitly distinguished by the different degrees of impacts of the income and demographic variables. But the cross-sectional data used in these studies excluded price variables. Therefore, without estimating cross-price elasticities, these studies did not explicitly measure the extent of substitution between domestic and outbound tourism demand.

On the other hand, using aggregate time-series data, Hamal (1997) and Holmes and Shamsuddin (1997) quantified the substitution effect between travelling domestically and abroad. Both studies used single-equation demand models, in which both domestic and foreign tourism prices were included, thus allowing for estimation of cross-price elasticities and verification of substitutability. The limitations of single-equation demand models are well noted, such as lacking an explicit basis in consumer demand theory, and being unable to test such theoretical restrictions as symmetry and adding-up that are associated with existing demand theories (Li, Song, \& Witt, 2004, 2006). Hamal (1997) acknowledged that the most appropriate way to investigate the substitutability is to estimate a complete demand system that is consistent with economic theory. However, due to data limitations, Hamal (1997) did not implement system modelling. The AIDS model, with its rigorous theoretical underpinning, can serve this research purpose well, and is thus selected for the present study. This study serves as the first attempt in the context of analysing the substitution between Australian domestic and international outbound tourism with a system-of-equations approach.

\subsection{AIDS Modelling}


The AIDS model was originally developed by Deaton and Muellbauer (1980). Economic theory of consumers' demand underpins the AIDS model, in which all goods under investigation are represented in a system of equations and are analysed simultaneously. Expenditure elasticities, own-price elasticities, and cross-price elasticities can be calculated using AIDS estimates. In particular, the sign of the calculated cross-price elasticity indicates the relationship between the two products being concerned. A positive sign suggests substitution while a negative sign suggests complementarity. In addition, the homogeneity and symmetry restrictions of demand theory can be tested within the AIDS framework. Applications of AIDS modelling in tourism studies have largely been of a static form (from here on referred to as STATIC-AIDS), in which case the results can be interpreted as the longrun behaviour of tourism demand if the cointegration relationship holds (see De Mello, Park, \& Sinclair, 2002, Han, Durbarry, \& Sinclair, 2006, Papatheodorou, 1999).

However, various demand studies have shown that demand systems often deviate from their long-term equilibrium (Anderson \& Blundell, 1983; Lyssiotou, 2000, Duffy, 2003, De Mello and Fortuna, 2005). Thus the STATIC-AIDS specification, without incorporating the dynamic adjustment mechanism in the short run, often fails the tests for theoretical restrictions such as homogeneity and symmetry, and the subsequent long-run elasticity estimates may not be accurate (Edgerton, Assarsson, Hummelmose, Laurila et al., 1996). In tourism studies, Cortés-Jiménez, et al. (2009), Durbarry and Sinclair (2003), Li, et al. (2004, 2006) and $\mathrm{Wu}, \mathrm{Li}$, and Song (2011) incorporated error correction (EC) mechanisms into AIDS modelling (from here on referred to as EC-AIDS model). Empirical evidence has shown that EC-AIDS models can improve theoretical conformability as well as the forecasting performance (see, for example, Cortés-Jiménez et al., 2009, Li et al., 2004).

The applications of AIDS models in international tourism studies can be broadly grouped into two types of demand analyses: (a) tourists' expenditure allocation among a number of selected international destinations (e.g., De Mello et al., 2002, Han et al., 2006, Papatheodorou, 1999); (b) tourists' budget allocation among different product categories such as accommodation, food and drinks, and shopping in an outbound destination (e.g., Fujii, Khaled, \& Mak, 1985, Wu et al., 2011). The substitution or complementary relationships among different outbound destinations and among different tourism product categories can be investigated through the calculated cross-price elasticities. In the studies where alternative outbound destinations were considered, the price variables of the AIDS model often takes a relative form, that is, the price of each destination relative to that of the country of origin (i.e., domestic tourism price). The substitution relationship between domestic and outbound tourism is not explicitly tested as their main objective was to analyse the level of competition amongst outbound destinations and the domestic equation is not included. Thus far, no attempt has been made to carry out any empirical study using this system-of-equations model, in which domestic destinations and outbound destinations are explicitly treated as potentially substitutable products. This paper therefore aims to bridge the gap in the literature. Given the alarming situation of domestic tourism in Australia 
as outlined in the Introduction, this study aims to investigate the substitution relationships between Australian domestic tourism and outbound tourism in key destination countries and regions, and draw some useful policy implications based on the empirical findings.

\section{METHODOLOGY}

Assuming a priori weak separability of goods and services, an assumption necessary for practical reasons and common in demand system studies (Pollak \& Wales, 1992), we argue that tourism consumption of Australians follows a three-stage budgeting process, much in line with the past literature such as Eugenio-Martin and Campos-Soria (2011), Nicolau and Más (2005) and van Soest and Koorerman (1987). In Stage one, Australians budget for tourism spending and non-tourism spending. In Stage two, Australians budget between spending on domestic tourism and outbound tourism. In Stage three, specific destination choice either domestically or abroad is considered. Given the research aim and data limitations, Stages two and three are combined in the following empirical model.

Practicality and data availability dictate that outbound tourism cannot be looked at for all the countries that Australians visit. We select the following key outbound destination countries: the US, the UK, New Zealand, Japan, Hong Kong, Singapore, Malaysia, Indonesia, and Thailand. Total outbound tourism expenditure to these destination countries contributed to more than $50 \%$ of total Australian outbound expenditure over our sample period. Ideally, we would like to have included more countries. Unfortunately samples taken by Tourism Australia do not cover some of the less popular destination countries or these are simply grouped as "Others". This makes their exclusion from our AIDS model inevitable as we do not have the necessary price information for these. Furthermore, given the relatively short time series length, the six Asian countries are combined as "Asia" region. We present details on this in the Section 3.7. In what follows we provide a brief explanation of the STATIC-AIDS and EC-AIDS specifications, and then pay particular attention to the development of a new price variable for this framework.

\subsection{STATIC-AIDS}

A static AIDS model for modelling the demand of tourism by Australians can be written as

$$
w_{i t}=\alpha_{i}+\sum_{j} \gamma_{i j} \ln p_{j t}+\beta_{i} \ln \frac{x_{t}}{p_{t}}+\varepsilon_{i t}
$$

Where $w_{i t}$ is tourism destination i's budget share in Australian tourism expenditure at time $\mathrm{t}) ; p_{j t}$ is the price measure of tourism products at tourist destination $j$ at time $t ; i, j=1, \ldots, \mathrm{N}$ denote tourist destinations: Australia (for domestic tourism), Asia, US, UK, and New Zealand, respectively; $\mathrm{N}=5$ the number of total tourist destinations considered; $x_{t}$ is the total expenditure on all tourist destinations in the system at time $t ; p_{t}$ is the aggregate price index at time $t ; \frac{x_{t}}{p_{t}}$ is the real total expenditure per capita at time $t$; and $\varepsilon_{i t}$ is the iid normal 
disturbance term. $\alpha_{i}, \gamma_{i j}$, and $\beta_{i}$ are unknown parameters to be estimated. $\gamma_{i j}$ 's represent the long-run effect of price changes on the budget shares of various tourist destinations while the $\beta_{i}$ 's represent the long-run effect of the overall expenditure budget changes on the budget allocation.

Among a number of aggregate price indices being proposed in the literature, the Tornqvist (1936) index has superior properties such as being exact for linearly homogeneous functions and is more likely to generate unbiased expenditure and price elasticities (see $\mathrm{Wu}$ et al. (2011) for further discussions). Therefore in this study we use the Tornqvist index, which is computed as

$$
p_{t}=\prod_{i=1}^{N}\left(\frac{p_{i t}}{p_{i 0}}\right)^{\widetilde{w}_{i t}}
$$

with weight $\widetilde{w}_{i t}$ is defined as

$$
\widetilde{w}_{i t}=\left(w_{i t}+w_{i 0}\right) / 2 \text {, }
$$

where $w_{i}{ }^{\prime}$ s are positive and add up to 1 , and $\mathrm{t}=0$ represents the base period.

\subsection{EC-AIDS}

The STATIC-AIDS model of equation (1) assumes that the consumption behaviour of Australian tourists is always in equilibrium. However, in the short term the demand system is likely to be in disequilibrium. Therefore, to capture tourists' dynamic behaviours over time, a dynamic demand system should incorporate the mechanism of short-run adjustment towards the long-run equilibrium. Past AIDS studies employed various dynamic specifications (e.g., Anderson \& Blundell, 1983, Durbarry \& Sinclair, 2003, Lyssioutou, 2000). The following EC-AIDS specification is widely used in past empirical studies (e.g., Chambers \& Nowman, 1997, Duffy, 2003) and has been shown to be appropriate for tourism demand analysis (e.g., Durbarry \& Sinclair, 2003, Li, et al., 2006).

$$
A(L) w_{t}=B(L) z_{t}+\varepsilon_{t}
$$

where $w_{t}$ is a $(N \times 1)$ vector of budget shares observed at time $t$, and $z_{t}$ is a $[(N+2) \times 1]$ vector of intercepts, $N$ price variables, and real expenditure per capita, observed at time $t$. $A(L)=I+\sum_{k=1}^{l} A_{k} L^{k}$ and $B(L)=I+\sum_{k=0}^{m} B_{k} L^{k}$ are matrix polynomials in the lag operator $L$. In theory, information criteria can be used to determine the optimal lag lengths of $I$ and $m$, starting with arbitrarily high orders. In practice, demand systems are often heavily parameterized with limited number of observations in the time dimension, which makes the sequential testing of lag lengths impossible. The EC-AIDS model of Equation (2) suggests that current budget share movements depends on not only current changes both standard AIDS explanatory variables (i.e., $p_{j t}$ and $\frac{x_{t}}{p_{t}}$ ) but also adjustments to consumer 
disequilibrium in the previous period through an error correction process (Durbarry \& Sinclair, 2003).

Given the short length of the time series, we restrict our model to a parsimonious first order system in levels. In its error correction form, Equation (2) becomes a dynamic EC-AIDS model:

$$
\Delta w_{i t}=\lambda \mu_{i, t-1}+\sum_{j} \gamma_{i j}^{*} \Delta \ln p_{j t}+\beta_{i}^{*} \Delta \ln \frac{x_{t}}{p_{t}}+\varepsilon_{i t}^{*}
$$

Where $\Delta$ is the difference operator. $\mu_{i, t-1}$ is the error correction term that measures the disequilibrium for the $i$ th budget share equation in the previous period, and it is the estimated residual from the $i$ th STATIC-AIDS equation. $\lambda$ measures the extent to which the $i$ th equation adjusts to its own budget share allocation disequilibrium at time $t-1$. As a parsimonious specification and in line with past empirical studies such as Durbarry and Sinclair (2003) and Edgerton et al. (1996), the value of $\lambda$ is assumed to be identical for all equations. This implies a restricted assumption that the speed of consumers' short-run adjustment to the long-run equilibrium is the same across all products in the system. A full specification would take into account that the change of each expenditure share adjusts with respect to not only its own disequilibrium, but also the disequilibrium of each of the other products in the system (Duffy, 2003). However, such a full specification consumes a large number of degrees of freedom, which has restricted its application in tourism demand studies. It is easy to see that Equation (3) captures both short-run and long-run dynamics. In the short run, where disequilibrium exists, budget share responds to changes in prices, real expenditure per capita, and disequilibrium from the previous period. In the long run, where the system reaches its steady state, all differenced terms become zero, in which case Equation (3) becomes Equation (1).

\subsection{Theoretical Restrictions and Estimation}

The AIDS models are derived from economic demand theory, and as a result a set of theoretical restrictions must be satisfied (Deaton \& Muellbauer, 1980). More specifically, they are:

(i) Adding up:

$$
\begin{gathered}
\sum_{i} \alpha_{i}=1 ; \sum_{i} \beta_{i}=0 ; \sum_{i} \gamma_{i j}=0 \text { in Equation(1) } \\
\sum_{i} \beta_{i}^{*}=0 ; \sum_{i} \gamma_{i j}^{*}=0 \text { in Equation(3) }
\end{gathered}
$$

(ii) Homogeneity:

$$
\sum_{j} \gamma_{i j}=0 \text { in Equation (1) }
$$




$$
\sum_{j} \gamma_{i j}^{*}=0 \text { in Equation(3) }
$$

(iii) Slutsky symmetry:

$$
\begin{aligned}
& \gamma_{i j}=\gamma_{j i} \text { in Equation (1) } \\
& \gamma_{i j}^{*}=\gamma_{j i}^{*} \text { in Equation(3). }
\end{aligned}
$$

The adding-up condition implies that budget shares must always sum to unity. The homogeneity condition implies that a proportional change in all prices and real expenditure does not alter quantities purchased and budget allocations. The symmetry condition implies a symmetric substitution matrix and consumer preferences are consistent. The adding-up condition needs not be tested and is easily satisfied by omitting one equation from the system when estimating the model. The coefficients of the omitted equation can be calculated after using the adding-up rule if needed. Homogeneity can be tested equation-byequation, while symmetry can only be tested for the entire system as it involves crossequation restrictions. Both STATIC-AIDS and EC-AIDS models are typically estimated using Zellner's (1962) seemingly unrelated regression procedure, which accounts for contemporaneous correlations across equations and is more efficient than equation by equation ordinary least squares estimation.

\subsection{Calculation of Demand Elasticities}

Demand elasticities are computed using coefficient estimates from the AIDS model. Specifically,

$$
\begin{aligned}
& \text { expenditure elasticity: } \eta_{i}=\frac{\beta_{i}}{w_{i}}+1 \\
& \text { uncompensated price elasticity: } \psi_{i j}=\frac{\gamma_{i j}-b_{i} w_{j}}{w_{i}}-\delta_{i j} \\
& \text { compensated price elasticity: } \psi_{i j}=\frac{\gamma_{i j}+w_{i} w_{j}}{w_{i}}-\delta_{i j}
\end{aligned}
$$

where $\delta_{i j}$ is the Kronecker delta, which is a function of index $i$ and $j . \delta_{i j}$ is equal to 1 for $i=j$, and 0 otherwise. As budget shares are observed $T$ times during the sample period, all elasticities are calculated at the sample means of the budget shares. Standard errors of the elasticities are computed based on the estimated variance covariance matrix of the AIDS model's coefficients. It should be noted that, the uncompensated price elasticity measures how a change in the price of one product affects the demand for this product and other products with the total expenditure and other prices held constant, while the compensated price elasticity measures the price effect on the demand assuming the real expenditure $(x / p)$ remains constant. In particular, the sign of a calculated compensated elasticity indicates the 
substitutability or complementarity between the products under consideration (Edgerton et al., 1996). Therefore, this study focuses on compensated price elasticities.

\subsection{A Commonly Used Price Variable}

In many demand studies involving prices measured at different countries denominated in different currencies, the price variable for origin country $i$ relative to destination country $j$ is constructed as:

$$
p_{j, t}=\frac{C P I_{j, t} / C P I_{i, t}}{E X_{j, t} / E X_{i, t}}
$$

where at time $t, C P I_{j, t}$ and $C P I_{i, t}$ are consumer price indices as proxies of tourism prices for the destination country $j$ and the origin country $i$, respectively;. $E X_{j, t}$ and $E X_{i, t}$ are exchange rates against the US dollar for the destination country and the origin country; all indexed to be 100 for a given base year (e.g., Han et al., 2006). In our empirical study, the origin country $i$ is always Australia. A higher rate of inflation in country $j$ would result in a higher $C P I_{j, t}$ and a larger $p_{j, t}$ over time, reflecting the higher cost for Australians travelling to destination $j$. On the other hand, depreciation of country $j$ 's currency would result in a higher $E X_{j, t}$ and a smaller $p_{j, t}$, representing a reduced cost for Australians travelling to destination $j$. Thus, $p_{j, t}$ as computed in Equation (4) can adequately capture the temporal price movements of destination country $j$ relative to original country $i$.

\section{\{insert Figure 2 here}

However, this price variable is not without its limitations. Figure (2) shows the quarterly prices constructed using Equation (4) for the five tourist destinations under consideration in our study. For instance, the price series for UK is computed as: $p_{U K, t}=\frac{C P I_{U K, t} / C P I_{A U S, t}}{E X_{U K, t} / E X_{A U S, t}}$. Firstly, the domestic series exhibits no price movements. This is due to the fact that for domestic travellers, destination $j$ of the tourist and origin $i$ of the tourist are the same, which cancels out in both the numerator and the denominator. This is not ideal, as temporal price movements are needed if one were to estimate both own and cross price elasticities for domestic prices.

Secondly, these prices cannot be used to represent the relative levels of the tourist destinations, and are therefore not directly comparable. For instance, Asia is shown to have a higher price level than the US, while UK would be the cheapest tourist destination from 2009 onwards, which are both unlikely to be true. Moreover, both $C P I_{j, t}$ and $E X_{j, t}$ in Equation (4) are indexed to a certain base year. If the base year chosen for $C P I_{j, t}$ is the same as that chosen for $E X_{j, t}$ for all destinations, $C P I_{j, \text { BaseYear }}=E X_{j, \text { BaseYear }}=100 \forall j$. We would have a curious result where all destination countries have the same price value for that particular base year. As highlighted in Forsyth and Dwyer (2009), "this (relative price 
variable) involves a measure of changes in price competitiveness, but it does not measure the actual of price competiveness".

\subsection{A PPP-based Price Variable}

Forsyth and Dwyer (2009) provided a comprehensive summary of potential price measures for tourism competitiveness studies. Of the list of indicators that were found to provide meaningful cross-country comparisons, purchasing power parity (PPP), which is defined as "the number of currency units required to buy goods equivalent to what can be bought with one unit of the currency of the base country; or with one unit of the common currency of a group of countries" (United Nations, 1992), was identified as the most broadly available and general indicator. Therefore, in the context of AIDS modelling for tourism demand, we propose a new price variable constructed based on PPP.

Specifically, we replace CPI in Equation (4) with PPP:

$$
P_{j, t}=\frac{P P P_{j, t} / P P P_{i, t}}{E X_{j, t} / E X_{i, t}} \times 100
$$

where $P P P_{j, t}$ and $P P P_{i, t}$ are $P P P$ observed at time $t$ in tourist destination $j$ and tourist origin $i$ (which in our case is always Australia) respectively. But just as in the case of the price variable based on CPI/EX ratios, $P_{j, t}$ from Equation (5) will always be equal to 1 for the domestic price series as $j=i=$ Australia for all $t$. To circumvent this problem, we note that the Penn World Table (PWT) version 7.0, which periodically releases measures of PPP and national accounts (see Deaton \& Heston, 2010, for a detailed discussion), also publishes the following two measures:

$$
C G D P_{j, t}
$$

which is called the PPP converted GDP per capita of country $j$ at current prices in USD, and it is essentially the ratio of GDP per capita over PPP; and

$$
R G D P_{j, t \mid 2005}
$$

which is called the PPP converted GDP per capita of country $j$ at 2005 constant prices in USD and is derived using the Laspeyres method. We suggest computing the following measure:

$$
P P P_{j, t \mid 2005}=\frac{C G D P_{j, t}}{R G D P_{j, t \mid 2005}} \times P P P_{j, t}
$$

which we shall call $P P P$ at 2005 constant prices. $P P P_{j, t \mid 2005}$ is a $P P P$ measure augmented by $\frac{C G D P_{j, t}}{R G D P_{j, t \mid 2005}}$, which is a GDP ratio of GDP at current prices and GDP at prices of a base year (2005 in this case). Finally, in Equation (5) replacing $P P P_{j, t}$ with $P P P_{j, t \mid 2005}$ results to

$$
P_{j, t \mid 2005}=\frac{P P P_{j, t \mid 2005} / P P P_{i, t}}{E X_{j, t} / E X_{i, t}} \times 100,
$$


the new price variable used in our empirical study. Compared to the commonly used price variable of Equation (4), the new price variable allows: (a) valid cross-sectional comparison of price levels as it is based on PPP measures; (b) temporal variations irrespective to which country is chosen as the base country, as it is augmented by a GDP ratio denominated by a fixed base year price level. Figure (3) shows yearly evolutions of the new relative price variables for the five tourist destinations in our study from year 2000 to year 2009. Asia is seen as the least expensive destination, while Australia shows a steady increasing trend over time. In comparison to Figure (2), these price series are much more in line with our prior expectation on the relative levels of the tourist destinations in our study.

\{Insert Figure 3 about here $\}$

\subsection{Data Description}

We measure Australian tourism demand with overnight expenditure. For domestic tourism, we use the aggregate expenditure by all purposes of travel and across all states. In terms of outbound demand, we consider the US, the UK, New Zealand, and Asia as the four main overseas destinations. For Asia we include Japan, Hong Kong, Singapore, Malaysia, Indonesia, and Thailand. The reason for combining six Asian countries into one destination region is due to the short data series available. Including these countries individually in the AIDS models would consume over 50 more degrees of freedom, and thus a simultaneous estimation of the AIDS models would be infeasible.

Therefore we compute the price variable for ASIA as the weighted average,

$$
P_{A S I A, t \mid 2005}=\sum_{j=1}^{6} P_{j, t \mid 2005} w_{j, t}
$$

where $j=1,2, \ldots, 6$ represent Japan, Hong Kong, Singapore, Malaysia, Indonesia, and Thailand respectively. $p_{j, t \mid 2005}$ is the price level of the $j$ th country at time $t$, as given by Equation (6), and $w_{j, t}$ is the tourism expenditure budget share of the jth country (see Song et al., 2010, and references therein, for similar implementations of such weighted averages in the tourism literature).

We have quarterly expenditure data covering the period of 2000Q1 to 2010Q3, giving us 43 observations in the time dimension. We seasonally adjust the data prior to estimation using the multiplicative method in EViews 7. Both domestic and outbound data come from the National Visitors Survey managed by Tourism Research Australia (Tourism Research Australia, 2010).

Figure 4 shows the budget share for Australian domestic tourism over the sample period. It is clear that the expenditure share of domestic tourism has experienced a steady decline over the decade. From a peak of over $80 \%$ during $2000-2004$ it has fallen to about $70 \%$ in year 2010. 
\{Insert Figure 4 about here\}

Figure 5 shows the tourism budget shares of the overseas destinations. In contrast to domestic tourism expenditure shares of overseas destinations all experienced increases, suggesting that Australians are increasingly substituting domestic travel with overseas travel. In particular, Asia has the highest budget share amongst all four overseas destinations. This is due to a combination of factors such as its close spatial proximity, relatively lower costs, and strong cultural connections due to the presence of a large Asian migrant community in Australia.

\section{\{Insert Figure 5 about here $\}$}

In terms of the price variables, as PWT version 7.0 only publishes PPP data an anual frequency, the modified relative price level of GDP of Equation (6) can only be calibrated annually. In order to apply this price variable in our study, we need to convert it to quarterly frequency. We model the modified relative price level of GDP of Equation (6) to be a function of: the domestic price level of country $j$, the Australian price level and the exchange rate of country $j$ denoted in Australian dollar (AUD). Therefore we write:

$$
P_{j, t \mid 2005}^{y r}=\beta_{0}+\beta_{1} C P I_{j, t}^{y r}+\beta_{2} C P I_{A U D, t}^{y r}+\beta_{3} \frac{E X_{j, t}^{y r}}{E X_{A U S, t}^{y r}}+e_{t}
$$

where $P_{j, t \mid 2005}^{y r}, C P I_{j, t}^{y r}, C P I_{A U D, t}^{y r}$, and $\frac{E X_{j, t}^{y r}}{E X_{A U S, t}^{y r}}$, are observations at the yearly frequency. Equation (7) is estimated by OLS. The $\mathrm{R}^{2} \mathrm{~s}$ for each of the regressions are respectively: $99.24 \%, 95.87 \%, 86.22 \%, 87.69 \%$ and $97.35 \%$, showing satisfactory model fits.

We next project this relationship based on annual averages to a relationship based on quarterly averages,

$$
\hat{P}_{j, t \mid 2005}^{q r t}=\hat{\beta}_{0}+\hat{\beta}_{1} C P I_{j, t}^{q r t}+\hat{\beta}_{2} C P I_{A U D, t}^{q r t}+\hat{\beta}_{3} \frac{E X_{j, t}^{q r t}}{E X_{A U S, t}^{q r t}}
$$

where $\hat{\beta}_{0}, \hat{\beta}_{1}, \hat{\beta}_{2}$, and $\hat{\beta}_{3}$ are the OLS estimates from Equation (7). $\hat{P}_{j, t \mid 2005}^{q r t}$ is the fitted quarterly value of the price variable, and $C P I_{j, t}^{q r t}, C P I_{A U D, t}^{q r t}$ and $\frac{E X_{j, t}^{q r t}}{E X_{A U S, t}^{q r t}}$ are all observed quarterly values.

Finally, we apply the following standardization factor:

$$
\zeta_{j, t}^{q r t}=\frac{P_{j, t \mid 2005}^{y r}}{\sum_{q t r} \hat{P}_{j, t \mid 2005}^{q r t} / 4}
$$

where $\sum_{q t r} \hat{P}_{j, t \mid 2005}^{q r t} / 4$ results to the annual average aggregate of the quarterly fitted values within each year so that 


$$
\hat{P}_{j, t \mid 2005}^{q r t}=\hat{P}_{j, t \mid 2005}^{q r t} \times \zeta_{j, t}^{q r t}
$$

is our proposed modified relative price level of GDP (as defined in Equation 6) fitted for quarterly data. Note that $\zeta_{j, t}^{q r t}$ is merely an adjustment factor. It guarantees that the sum of the fitted quarterly prices for any given year is equal to the observed yearly value. Since $P_{j, t \mid 2005}^{y r}$ is only observed up to year 2009, quarterly prices in year 2010 are forecasted using Equation (8). Figure 6 displays the yearly $P_{j, t \mid 2005}^{y r}$, the quarterly $\hat{P}_{j, t \mid 2005}^{q r t}$, and modified quarterly values $\hat{P}_{j, t \mid 2005}^{q r t}$ for the domestic price variable as an example. The $\hat{P}^{\text {qrt }}$ series projects the relationship in Equation (7) estimated at the yearly frequency to quarterly values. $\hat{\hat{P}}^{q r t}$ are the standardised values, so that the sum of quarterly values within a year is equal to the observed yearly value. It should be noted that the approach of interpolation and adjustment we apply here is in the same spirit as Chow and Lin $(1971,1976)$, Fernandez (1981), and Litterman (1983), in which OLS estimates based on low-frequency data (in our case annual data) are used as best linear unbiased interpolators of high-frequency data (in our case quarterly data) augmented by summation equality between annual and quarterly values. Abeysinghe and Lee (1998) also apply such methods in order to interpolate Malaysian annual GDP to quarterly.

\{Insert Figure 6 about here\}

Figure 7 displays the quarterly modified relative price level of GDP for all the destinations considered in this study. Overall the price level of Asia remains low compared to the other destinations, although the gap has closed considerably except against domestic Australian tourism. The price level of Australia has experienced a steady increase over the years. The price level of New Zealand followed a similar trajectory to that of Australia until roughly year 2006, when its price increase slowed and started to become relatively cheaper compared to Australia. Both the US and the UK were much more expensive than the other three destinations at the beginning of the sample period, but the gap was significantly reduced over the decade. While the US, the UK, and NZ are still more expensive than Asia in general, all four destinations are now cheaper than Australia. Finally it is also clear that the domestic price series is a lot less volatile than the price series for overseas destinations. This is to be expected, as from an Australian perspective, variations in exchange rates would play no part in the price level of domestic travels.

$$
\text { \{Insert Figure } 7 \text { about here\} }
$$

\section{EMPIRICAL RESULTS}

Both long-run STATIC-AIDS and short-run EC-AIDS models are estimated, and theoretical restrictions are tested. Based on the final model estimates, long-run and short-run demand elasticities are calculated. In particular, cross-price elasticities quantify the degree of substitution between domestic tourism and outbound tourism to key destinations.

\subsection{Model Estimation and Theoretical Restriction Tests}


To estimate the STATIC- and EC-AIDS models, we initially exclude New Zealand from our system estimation. The coefficients of the omitted New Zealand equation are subsequently calculated using the adding-up rule. We sequentially test for theoretical restrictions (as in Wu, et al., 2011). Specifically, we first estimate the AIDS models fully unrestricted. We then estimate the models with homogeneity restrictions imposed. Finally, we estimate under both homogeneity and symmetry. The first test is carried out via imposing homogeneity on the fully unrestricted model, the second test is carried out via imposing symmetry restrictions on the homogeneity-restricted model, and the third test is carried out via imposing both symmetry and homogeneity restrictions on the fully restricted model. For the STATIC-AIDS model, the Wald statistics are summarized in the first column of Table1. None of the theoretical restrictions are satisfied for the STATIC-AIDS specification as the null hypothesis is rejected at a $1 \%$ level of significance in all three tests. The lack of short-run dynamics in the model is most likely the cause of these restrictions not being satisfied as the past literature has argued (e.g., Edgerton et al., 1996).

\{Insert Table 1 about here\}

We estimate the EC-AIDS with SUR using the residual series generated from the estimated STATIC-AIDS model. In order for the error correction representation of the EC-AIDS model to be valid, long-run equilibrium relationships of the demand system must be established, i.e., the residual series from STATIC-AIDS estimation have to be stationary. The Augmented Dickey-Fuller (ADF) test is applied to test for the stationarity of the residual series. The residual series of the Domestic equation is found to be stationary at $5 \%$ significance level, while the residual series of all remaining equations are found to be stationary at $1 \%$ significance level. This suggests that the STATIC-AIDS model provides an adequate representation of the long-run equilibrium state of the system and short-run dynamics can be represented in an error correction form. Again we test for the theoretical restrictions sequentially, and the Wald statistics are summarized in the second column of Table 1.

The results show that the EC-AIDS specification passes all the restriction tests, at least at the $1 \%$ significance level. This suggests that the theoretically restricted EC-AIDS model is adequately specified and the calculated elasticities reflect accurately Australian residents' short-term tourism consumption behaviour. We present estimation results for both the long-run model (in Table 2) and the short-run model (in Table 3). Even though the static long-run model does not pass the tests of theoretical restrictions, and the estimated longrun elasticities may not be precise, they still provide a useful foundation for comparisons against the results of the dynamic short-run model, and for drawing some general policy implications. It should be noted that we report the restricted STATIC-AIDS in Table 2, and it is the residual terms of this model that were incorporated into the EC-AIDS. Even though the STATIC-AIDS failed the restriction tests, it is believed that the reason is mainly related to the model specification, and these theoretical restrictions should be considered valid in the long run. With regard to the estimates of the EC-AIDS, the EC term in the EC-AIDS is significant at 
the $1 \%$ level, suggesting the presence of strong short-run dynamics. Its negative value (0.621 ) is consistent with an error correction mechanism.

\{Insert Table 2 about here\}

\{Insert Table 3 about here\}

\subsection{Long-Run and Short-Run Elasticities}

As have been shown earlier, the EC-AIDS model satisfies both homogeneity and symmetry restrictions, thus these results are likely to be more representative of the true consumer behaviour of Australian tourists in the short run. Long-run elasticities may be subject to some degrees of inaccuracy, but they still provide useful indications on the general patterns of Australian tourists' long-run tourism consumption behaviour. Table 4 summarizes the long-run and short-run expenditure elasticity estimates from the dynamic EC-AIDS model. All estimated expenditure elasticities are positive and statistically significant. In line with economic theory and past empirical studies (e.g., Li et al., 2004), among all destinations long-run elasticities are higher than their short-run counterparts except for domestic tourism, in which case long-run and short-run elasticities are still very close. The estimated expenditure elasticity for domestic tourism is less than 1 , consistent with the general belief that domestic tourism is treated as a necessity. The expenditure elasticities of the three of the four overseas destinations (Asia, the US, and the UK) are all greater than 1, consistent with past literature which commonly suggests that international tourism is considered a luxury good (Li et al., 2005). Lastly, the expenditure elasticity of New Zealand is less than 1, suggesting that ustralian tourists treat tourism in New Zealand as a necessity, which is consistent with our expectations given the significant cultural and economic connections the two countries share and the very short distance between each other.

\section{\{Insert Table 4 about here\}}

Table 5 summarizes the long-run and short-run price elasticity estimates. Again, in line with demand theory, Australian tourists generally present higher degrees of responsiveness to price changes in the long run than in the short run. For the very few exceptions the long-run and short-run elasticity values are still very close. The diagonal entries are own-price elasticities, and they are all negative and significant in both the long run and short run, which are consistent with demand theory. For the majority of cases own-price elasticities values are between 0 and -1 , suggesting that the demand for tourism in these destinations are price-inelastic, except for the US in the long run and New Zealand in both long run and short run. In particular, the demand for Australian domestic tourism is the least price sensitive in both the long run and the short run. This is in line with demand theory which suggests that necessities tend to have more price-inelastic demand (Mankiw \& Taylor, 2006). This can also be explained by the relatively high portion of Australians' trips for visiting 
friends and relatives (VFR) purposes in domestic tourism compared to international tourism. The demand for VFR tourism is generally less price sensitive than leisure tourism.

It is also noted that, in the short run the demand for tourism in Asia is less price elastic ($0.418)$ than that for the US (-0.852) and the UK (-0.926). There are two possible reasons for this. First, as Figure 1 shows, the price level in Asia is much lower than that in the other two long-haul destinations; second, the destination of Asia is defined as a much broader region than individual countries. According to demand theory, the wider the defined market, the less price elastic the demand because it is harder to find close substitutes for broadly defined products (Mankiw \& Taylor, 2006). However, in the long run own-price elasticities tend to converge to some extent and the differences are not significant any more. The highest own-price elasticities (in absolute values, greater than 1 in both the long run and the short run) are shown in the case of New Zealand. This suggests that Australian demand for tourism in New Zealand is the most price elastic. This can be explained by the geographical proximity of the two countries and the relatively low cost of changing travel plans. For instance, a family that have planned a trip to the UK might not be willing to change their travel plans due to short term exchange rate movements as the trip is likely to have been planned thoroughly in advance. But the cost of changing travel plans to New Zealand, both financially and in terms of effort, is a lot lower, hence the higher responsiveness to relative price movements between the two countries.

\section{$\{$ Insert Table 5 about here\}}

With regard to cross-price elasticities (the off-diagonal elements of Table 5), we find that the long-run as well as short-run cross-price elasticities for Australia in the first column are all positive and significant, indicating that once the tourism price decreases in the overseas destinations, the demand for Australian domestic tourism are likely to be substituted by outbound tourism to these destinations. The substitution effect is the strongest for Asia, closely followed by New Zealand. This is not surprising, as both destinations are geographically very close to Australia and provide many tourism products similar to those provided in Australia. For instance the beaches of Bali or Thailand are considered by many Australians as close substitutes for the beaches in the Gold Coast, and the ski resorts in the south island of New Zealand as close substitutes for ski resorts in Australian alpine regions. These results are also consistent with the patterns observed in Figures 4 and 5, where the significant decrease in domestic tourism expenditure share is coincided most noticeably with the significant increase of Asia's tourism expenditure share.

In addition, negative own-price elasticities are observed between Asia and the UK in both the long run and the short run. These results suggest that the two destinations are likely to be complements for Australian tourists. Asia is the major connecting hub for Australians travelling to the UK (and Europe in general). It is not uncommon for Australians to plan their travel such that they spend time in both Asia (as the connecting stop-over) and the UK. Therefore, once a trip to the UK via Asia is considered, price increases in one destination is 
likely to lead to a reduction of spending in the other. Furthermore, relatively low degrees of complementarity between Asia and the US and substitution between the US and the UK are observed only in the short run. On the contrary, a low level of substitution between Asia and New Zealand is detected only in the long run.

\section{CONCLUSION}

This study is the first attempt to apply a system-of equation demand model to explicitly quantify the substitutability between domestic and outbound tourism. The empirical study focuses on Australia as the country of origin for domestic and outbound tourism, given its significantly widening tourism trade deficit in recent years. For the first time, the theoretical sound AIDS model, in both its static and dynamic forms, is applied to the domestic-outbound tourism substitution analysis. Since the traditional CPI-based relative tourism price variable is not applicable for this analysis, a new innovative price variable based on the PPP index published by the Penn World Table is developed. Short-run demand elasticities are calculated based on the estimates of the theoretically restricted EC-AIDS, which assist a scientific investigation of the substitution relationship between domestic and outbound tourism.

The findings of this study provide confirmatory evidence on the substitutability between Australia's domestic tourism and outbound tourism in such key destinations as Asia, the UK and the US. In addition, this study reveals that domestic tourism is regarded as a necessity by Australians, and their demand for domestic tourism is less price elastic than that for outbound tourism. These findings confirm the validity and necessity of Australia's tourism polies in promoting domestic tourism in recent years, such as the "See Australia" marketing initiative along with the "Domestic Tourism Initiative" (through See Australia) launched since 1999, and the "No Leave No Life" campaign launched in 2009 (OECD, 2003, Commonwealth of Australia, 2009).

Meanwhile, given the widening tourism trade deficit in recent years, this study calls for further policy considerations to continue to promote domestic tourism and reduce tourism trade deficit. Effective public-private partnership between Federal, State and Territory governments and the tourism industry is crucial to drive a sustainable development of domestic tourism. Industry stakeholders all need to play an active role in the development. Greater collaboration between industry stakeholders throughout the tourism value chain and knowledge transfer through best practice sharing will contribute to further improvements of the industry's overall performance. To maximise the benefits of the whole tourism industry, greater attention should be paid to the seasonal and regional balance of domestic tourism promotion. Discounting especially in low seasons is likely to be effective in attracting the more price-sensitive, lower-spending domestic tourists. In the present global economic recession, the downturn in inbound tourism led to excess capacities of tourism 
service providers. In this case lowering prices domestically is likely to attract more domestic demand to fill these excess capacities. In addition to pricing strategies, continuous product innovations may reduce the substitutability of domestic tourism by outbound travel.

This study is subject to some limitations. Firstly, a number of key tourist destinations such as other European and South American countries are omitted from this study. China, with whom Australia is increasingly connected with both socially and economically, is also excluded from this study due to lack of data. We hope that in the future sufficient amount of data on these destinations will be made available by Tourism Research Australia. The second limitation is related to the two-stage approach to cointegration analysis. Due to the small sample constraint, the long-run and short-run models were estimated in two separate stages. As a result, the estimated long-run elasticities may be subject to some degrees of inaccuracy. In the future once the sample size allows, a one-stage cointegration method should be employed. We also must acknowledge that consumer behaviour is ever changing and these price elasticities are likely to shift over time. With greater data availability in the future, we would like to extend our study to a time-varying parameter framework (see Li et al., 2006), which will allow us to identify temporal patterns in the estimated price elasticities for different destination regions.

\section{References}

Allen, D., Yap, G., \&Shareef, R. (2009). Modelling interstate tourism demand in Australia: A cointegration analysis. Mathematics and Computers in Simulation, 79(9), 2733- 2740.

Anderson, G., \& R. Blundell (1983).Testing restrictions in a flexible dynamic demand system: An application to consumers' expenditure in Canada. Review of Economic Studies, 50, 397-410.

Ashworth, J., \& Bergsma, J. R. (1987). New policies for tourism: Opportunities or problems? Tijdschriftvoor Economische en Sociale Geografie, 78(2), 151-152.

Ashworth, J., \& Johnson, P. (1990). Holiday tourism expenditure: Some preliminary econometric results. Tourism Review, (3), 12-19.

Athanasopoulos, G., \& Hyndman, R. J. (2008). Modelling and forecasting Australian domestic tourism. Tourism Management, 29, 19-31.

Australian Bureau of Statistics (2011). Tourism satellite account: Australian National Accounts, Catalogue No. 5249.0.

Baretje, R. (1982). Tourism's external account and the balance of payments. Annals of Tourism Research, 9(1), 57-67.

Buse, A., \& Chan, W. H. (2000). Invariance, price indices and estimation in almost ideal demand systems.Empirical Economics,25(3), 519-39.

Chambers, M. J., \& Nowman, K. B. (1997). Forecasting with the almost ideal demand system: Evidence from some alternative dynamic specifications. Applied Economics, 29, 93543. 
Commonwealth of Australia (2009). National Long-Term Tourism Strategy. Department of Resources, Energy and Tourism, Australian Government. Retrived August 14, 2012, from http://www.ret.gov.au/tourism/Documents/DRET\%20Tourism\%20Strategy.pdf.

Cortés-Jiménez, I., Durbarry, R., \&Pulina, M. (2009). Estimation of out bound Italian tourism demand: A monthly dynamic EC-LAIDS model. Tourism Economics, 15, 547-565.

Crouch, G. I. (1996). Demand elasticities in international marketing: A meta-analysis application to tourism. Journal of Business Research, 36(2), 117-136.

Crouch, G. I., \& Ritchie, J. R. B. (1999). Tourism, competitiveness, and societal prosperity. Journal of Business Research, 44, 137-152.

De Mello, M.M., Pack, A.,\& Sinclair, M.T. (2002). A system of equations model of UK tourism demand in neighbouring countries. Applied Economics, 34, 509-521.

Deaton, A., \& Heston, A. (2010). Understanding PPPs and PPP-based national accounts. American Economic Journal: Macroeconomics, 2(4), 1-35.

Deaton, A.,\& Muellbauer, J. (1980a). An almost ideal demand system. American Economic Review, 70(3), 312-326.

De Mello, M. M., \& Fortuna, N. (2005). Testing alternative dynamic systems for modelling tourism demand. Tourism Economics, 11(4), 517-537.

Deng, M., \& Athanasopoulos, G. (2011). Modelling Australian domestic and international inbound travel: a spatial-temporal approach.Tourism Management, 32(5), 10751084.

Divisekera, S. (2010). Economics of leisure and non-leisure tourist demand: A study of domestic demand for Australian tourism. Tourism Economics, 16(1), 117-136.

Duffy, M. (2003). Advertising and food, drink and tobacco consumption in the United Kingdom: A dynamic demand system. Agricultural Economics, 28(1), 21-70.

Durbarry, R., \& Sinclair, M.T. (2003). Market shares analysis: The case of French tourism demand. Annals of Tourism Research, 30(4), 927-941.

Edgerton, D. L., Assarsson, B., Hummelmose, A., Laurila, I. P., Rickertsen, K., \& Vale, P. H. (1996). The Econometrics of Demand Systems with Applications to Food Demand in the Nordic Countries. London: Kluwer Academic Publishers.

Eugenio-Martin, J. L. \& Campos-Soria, J. A. (2011). Income and the substitution pattern between domestic and international tourism demand. Applied Economics, 43(20), 2519-2531.

Forsyth, P., \& Dwyer, L. (2009). Tourism Price Competitiveness. The Travel \& Tourism Competitiveness Report (pp. 77-90). World Economic Forum.

Fujii, E. T., Khaled, M., \& Mak, J. (1985). An almost ideal demand system for visitor expenditures. Journal of Transport Economics and Policy, 19, 161-171.

Hamal, K. (1997). Substitutability between domestic and outbound travel in Australia. Pacific Tourism Review, 1(1), 23-33.

Han, Z., Durbarry, R., \& Sinclair, M.T. (2006). Modelling US tourism demand for European destinations. Tourism Management, 27(1), 1-10.

Holmes, R. A., \& Shamsuddin, A. F. M. (1997).Short- and long-term effects of world exposition 1986 on US demand for British Columbia tourism. Tourism Economics, 3, 137-60. 
Huybers, T. (2003). Domestic tourism destination choices - A choice modelling analysis. International Journal of Tourism Research, 5, 445-459.

Kim, J. H., \& Ngo, M. T. (2001).Modelling and forecasting monthly airline passenger flows among three major Australian cities. Tourism Economics, 7(4), 397-412.

Li, G., Song, H., \& Witt, S. F. (2005). Recent development in econometric modeling and forecasting. Journal of Travel Research, 44(1), 82-99.

Li, G., Song, H., \& Witt, S. F. (2004). Modeling tourism demand: A dynamic linear AIDS approach. Journal of Travel Research, 43(22), 141-150.

Li, G., Song, H., \& Witt, S.F. (2006). Time varying parameter and fixed parameter linear AIDS: An application to tourism demand forecasting. International Journal of Forecasting, 22, 57-71.

Lyssiotou, P. (2000). Dynamic analysis of British demand for tourism abroad. Empirical Economics, 25(3), 421-436.

Mankiw, N. G., \& Taylor, M. P. (2006). Economics. London: Thomson.

Organisation for Economic Co-operation and Development (OECD, 2003). National Tourism Policy Review of Australia. Paris: OECD.

Nicolau, J. L., \& Más, J. M. (2005). Stochastic modeling: A three-stage tourist choice process. Annals of Tourism Research, 32(1), 49-69.

Papatheodorou, A. (1999). The demand for international tourism in the Mediterranean region. Applied Economics, 31(5), 619-630.

Pearce, D. G. (1987). Tourism Today: A Geographical Analysis. Harlow: Longman.

Pearce, D. G. (1989). International and domestic tourism: Interfaces and issues. GeoJournal, 19(3), 257-262.

Pollak, R. A., \& Wales, T. J. (1992). Demand System Specification and Estimation. Oxford: Oxford University Press.

Pyo, S., Uysal, M., \& McLellan, R. (1991). A linear expenditure model for tourism demand. Annals of Tourism Research, 18(3), 443-454.

Seckelmann, A. (2002). Domestic tourism-a chance for regional development in Turkey? Tourism Management, 23(1), 85-92.

Seetaram, N. (2012). Estimating demand elasticities for Australia's international outbound tourism. Tourism Economics, 18(5), 999-1017.

Smeral, E., \& Witt, S. F. (1996). Econometric forecasts of tourism demand to 2005. Annals of Tourism Research, 23(4), 891-907.

Song, H., \& Li, G. (2008). Tourism demand modelling and forecasting: A review of recent research. Tourism Management, 29(2), 203-220.

Song, H., Li, G., Witt, S. F., \& Fei, B. (2010). Tourism demand modelling and forecasting : how should demand be measured ? Tourism Economics, 16(1), 63-81.

Stabler, M. J., Papatheodorou, A., \& Sinclair, M. T. (2010). The Economics of Tourism (2nd ed.). Routledge.

Sugiyarto, G., Blake, A., \&Sinclair, M. T. (2003). Tourism and globalization: Economic impact in Indonesia. Annals of Tourism Research,30(3), 683-701.

Tornqvist, L. (1936). The bank of Finland's consumption price index. Bank of Finland Monthly Bulletin, 10, 1-8. 
Tourism Australia (2011). Exchange rates: challenges and opportunities for Australian tourism. Retrieved from www.tourism.australia.com/enau/downloads/Exchange Rates.pdf

Tourism Research Australia. (2010). Travel by Australians, June Quarter 2010. Tourism Australia, Canberra.

Tourism Research Australia (2011a). Factors affecting the inbound tourism sector: The impact and implications of the Australian dollar, Tourism Australia, Canberra.

Tourism Research Australia (2011b). What is driving Australians' travel choices? Tourism Australia, Canberra.

Tourism Research Australia (2011c). International Visitors in Australia: March 2011 Quarterly Results of the International Visitor Survey, Tourism Australia, Canberra.

Tribe, J. (2011). The economics of recreation, leisure \& tourism, fourth edition. Oxford: Butterworth-Heinemann.

United Nations (1992). Handbook of the International Comparison Program, Series F No. 62, New York: United Nations.

van Soest, A., \& Kooreman, P. (1987). A micro-econometric analysis of vacation behaviour. Journal of Applied Econometrics, 2(3), 215-226.

Witt, S. F., Newbould, G. D., \& Watkins, A. J. (1992). Forecasting domestic tourism demand: application to Las Vegas arrivals data. Journal of Travel Research, 31(1), 36-41.

Wu, D. C., Li, G., \& Song, H. (2011). Analyzing tourist consumption: A dynamic system-ofequations approach. Journal of Travel Research, 50(1), 46-56.

Yap, G., \& Allen, D. (2011). Investigating other leading indicators influencing Australian domestic tourism demand. Mathematics and Computers in Simulation, 81(7), 13651374.

Zellner, A. (1962). An efficient method of estimating seemingly unrelated regressions and test for aggregation bias. Journal of the American Statistical Association, 57, 348-68. 
Table 1.Wald Test Statistics for Static and Dynamic AIDS Specifications

\begin{tabular}{lll}
\hline Null hypothesis & STATIC-AIDS & EC-AIDS \\
\hline Homogeneity & $62.096^{* *}$ & 2.143 \\
Symmetry conditional on Homogeneity & $50.455^{* *}$ & $15.410^{*}$ \\
Both homogeneity and symmetry & $128.083^{* *}$ & 5.173 \\
\hline $\begin{array}{l}\text { Note: }{ }^{*} \text { and** denote that the null hypothesis is rejected at the 5\% and 1\% } \\
\text { significance levels, respectively. }\end{array}$
\end{tabular}


Table 2.Estimation Results of the STATIC-AIDS

\begin{tabular}{|c|c|c|c|c|}
\hline & AUS & ASIA & USA & UK \\
\hline $\left.\ln (P \overline{\overline{(A U S}})_{t \mid 2005}\right)-\ln \left(\overline{\overline{P(N Z})_{t \mid 2005}}\right)$ & $\begin{array}{l}-0.187^{* *} \\
(-8.351)\end{array}$ & $\begin{array}{l}0.085^{* *} \\
(6.944)\end{array}$ & $\begin{array}{l}0.040 * * \\
(3.426)\end{array}$ & $\begin{array}{l}0.016^{*} \\
(2.177)\end{array}$ \\
\hline $\ln \left(P \overline{(\overline{A S I} A)_{t \mid 2005}}\right)-\ln \left(\overline{\overline{(N Z})_{t \mid 2005}}\right)$ & $\begin{array}{l}0.085^{* *} \\
(6.944)\end{array}$ & $\begin{array}{c}-0.003 \\
(-0.1751)\end{array}$ & $\begin{array}{l}-0.026^{*} \\
(-2.073)\end{array}$ & $\begin{aligned}-0.034 * * \\
(-4.483)\end{aligned}$ \\
\hline $\left.\left.\ln (P \overline{\overline{(U S A}})_{t \mid 2005}\right)-\ln (\overline{(P \overline{(N Z}})_{t \mid 2005}\right)$ & $\begin{array}{c}0.040 * * \\
(3.426)\end{array}$ & $\begin{array}{l}-0.026^{*} \\
(-2.073)\end{array}$ & $\begin{array}{c}-0.013 \\
(-1.048)\end{array}$ & $\begin{array}{c}0.009 \\
(1.371)\end{array}$ \\
\hline $\left.\ln (\overline{\overline{P(U K}})_{t \mid 2005}\right)-\ln \left(\overline{\overline{P(N Z})_{t \mid 2005}}\right)$ & $\begin{array}{l}0.016^{*} \\
(2.177)\end{array}$ & $\begin{array}{c}-0.034^{* *} \\
(-4.483)\end{array}$ & $\begin{array}{c}0.009 \\
(1.371)\end{array}$ & $\begin{array}{l}0.005 \\
(0.784)\end{array}$ \\
\hline $\ln \left(\frac{x_{t}}{p_{t}}\right)$ & $\begin{array}{l}-0.138 \\
(-1.553)\end{array}$ & $\begin{array}{c}0.059 \\
(1.539)\end{array}$ & $\begin{array}{c}0.051 \\
(1.293)\end{array}$ & $\begin{array}{c}0.036 \\
(1.371)\end{array}$ \\
\hline
\end{tabular}

Note: ${ }^{*}$ and ${ }^{* *}$ denote $5 \%$ and $1 \%$ significance levels, respectively. $t$-statistics are included in the parentheses. 
Table 3.Estimation Results of the EC-AIDS

\begin{tabular}{lllll}
\hline & AUS & ASIA & USA & UK \\
\hline$\Delta\left[\ln \left(\hat{\hat{P}}_{A U S, t \mid 2005}\right)-\ln \left(\hat{\hat{P}}_{N Z, t \mid 2005}\right)\right]$ & -0.052 & 0.015 & 0.000 & 0.008 \\
& $(-1.139)$ & $(0.722)$ & $(0.019)$ & $(0.422)$ \\
$\Delta\left[\ln \left(\hat{\hat{P}}_{A S I A, t \mid 2005}\right)-\ln \left(\hat{\hat{P}}_{N Z, t \mid 2005}\right)\right]$ & 0.015 & $0.041^{* *}$ & -0.021 & $-0.035^{* *}$ \\
& $(0.722)$ & $(2.854)$ & $(-1.908)$ & $(-3.365)$ \\
$\Delta\left[\ln \left(\hat{\hat{P}}_{U S, t \mid 2005}\right)-\ln \left(\hat{\hat{P}}_{N Z, t \mid 2005}\right)\right]$ & 0.000 & -0.021 & 0.007 & $0.023^{*}$ \\
& $(0.019)$ & $(-1.908)$ & $(0.473)$ & $(2.138)$ \\
$\Delta\left[\ln \left(\hat{\hat{P}}_{U K, t \mid 2005}\right)-\ln \left(\hat{\hat{P}}_{N Z, t \mid 2005}\right)\right]$ & 0.008 & $-0.035^{* *}$ & $0.023^{*}$ & 0.001 \\
& $(0.422)$ & $(-3.365)$ & $(2.138)$ & $(0.067)$ \\
\multicolumn{1}{|c}{$\Delta\left[\ln \left(\frac{x_{t}}{p_{t}}\right)\right]$} & -0.052 & 0.018 & 0.032 & 0.016 \\
& $(-0.908)$ & $(0.669)$ & $(1.098)$ & $(0.770)$ \\
EC term (same for all equations) & $-0.621^{* *}$ & $-0.621^{* *}$ & $-0.621^{* *}$ & $-0.621^{* *}$ \\
& $(-9.153)$ & $(-9.153)$ & $(-9.153)$ & $(-9.153)$ \\
\hline
\end{tabular}

Note: * and** denote $5 \%$ and $1 \%$ significance levels, respectively. t-statistics are included in the parentheses. 
Table 4.Long-Run and Short-Run Expenditure Elasticity Estimates

\begin{tabular}{llllll}
\hline & AUS & ASIA & USA & UK & NZ \\
\hline Long-run & $0.822^{* *}$ & $1.726^{* *}$ & $1.914^{* *}$ & $1.681^{* *}$ & $0.803^{*}$ \\
Short-run & $0.933^{* *}$ & $1.222^{* *}$ & $1.570^{* *}$ & $1.299^{* *}$ & $0.630^{*}$ \\
\hline
\end{tabular}

Note: ${ }^{* *}$ and ${ }^{*}$ denote $1 \%$ and $5 \%$ significance levels, respectively. 
Table 5.Long-Run and Short-Run Compensated Price Elasticity Estimates

\begin{tabular}{rcclll}
\hline & AUS & ASIA & USA & UK & NZ \\
\hline AUS LR & $-0.464^{* *}$ & $1.832^{* *}$ & $1.495^{* *}$ & $1.081^{*}$ & $2.101^{* *}$ \\
SR & $-0.290^{* *}$ & $0.960^{* *}$ & $0.784^{*}$ & $0.935^{*}$ & $1.596^{* *}$ \\
ASIA LR & $0.191^{* *}$ & $-0.954^{* *}$ & & $-0.575^{* *}$ & $-0.547^{*}$ \\
SR & $0.100^{* *}$ & $-0.418^{*}$ & -0.298 & $-0.583^{* *}$ & \\
USA LR & $0.107^{* *}$ & & $-1.180^{* *}$ & & \\
SR & $0.056^{*}$ & & $-0.825^{* *}$ & $0.502^{*}$ & \\
UK LR & $0.073^{* *}$ & $-0.372^{* *}$ & & $-0.848^{* *}$ & \\
SR & $0.063^{*}$ & $-0.377^{* *}$ & $0.474^{*}$ & $-0.926^{* *}$ & \\
NZ LR & $0.094^{* *}$ & $-0.236^{*}$ & & & $-1.538^{* *}$ \\
SR & $0.071^{* *}$ & & & & $-1.570^{* *}$ \\
\hline
\end{tabular}

Note: ${ }^{*}$ and** denote $5 \%$ and $1 \%$ significance levels, respectively. LR and SR indicate long-run and short-run elasticities, respectively. Statistically insignificant elasticities are omitted from the table. 

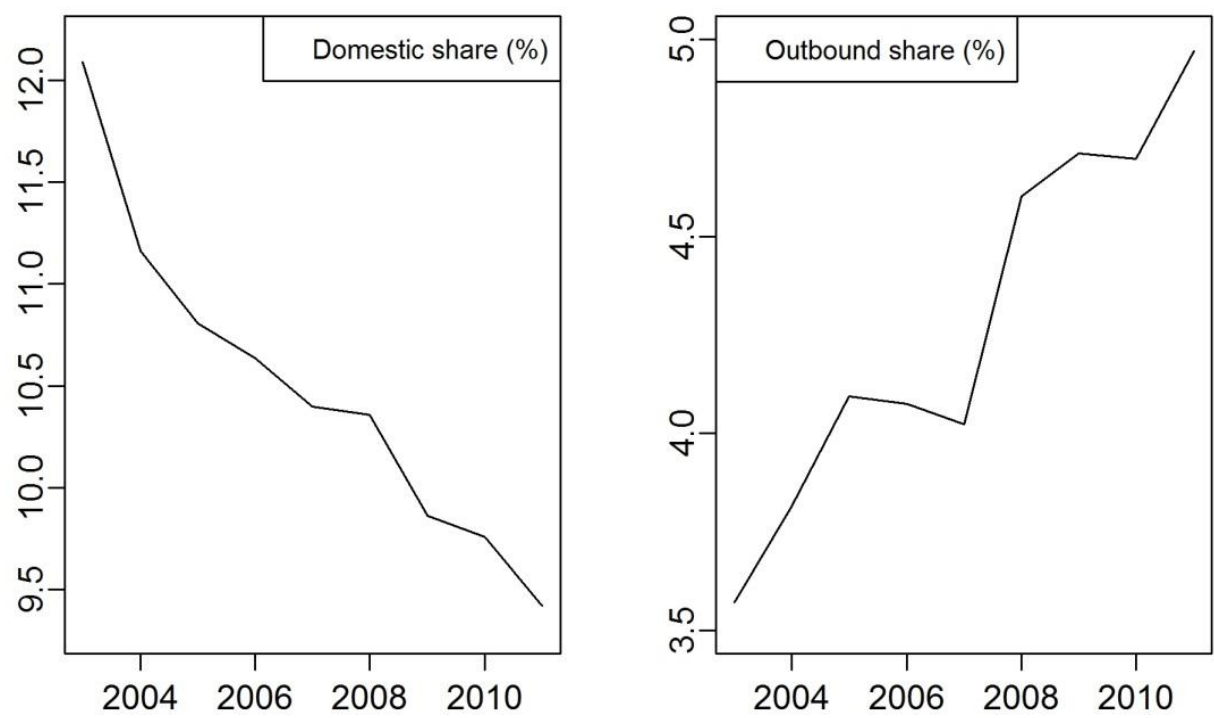

Figure 1. Domestic and Outbound Tourism Consumption of Australians as a Percentage of Household Final Consumption Expenditure

Sources: Australian Bureau of Statistics, Catalogue number 5249.0 - Australian National Accounts: Tourism Satellite Account, 2010-11 and Australian Bureau of Statistics, Catalogue number 5206.0 - Australian National Accounts: National Income, Expenditure and Product, Mar 2012 


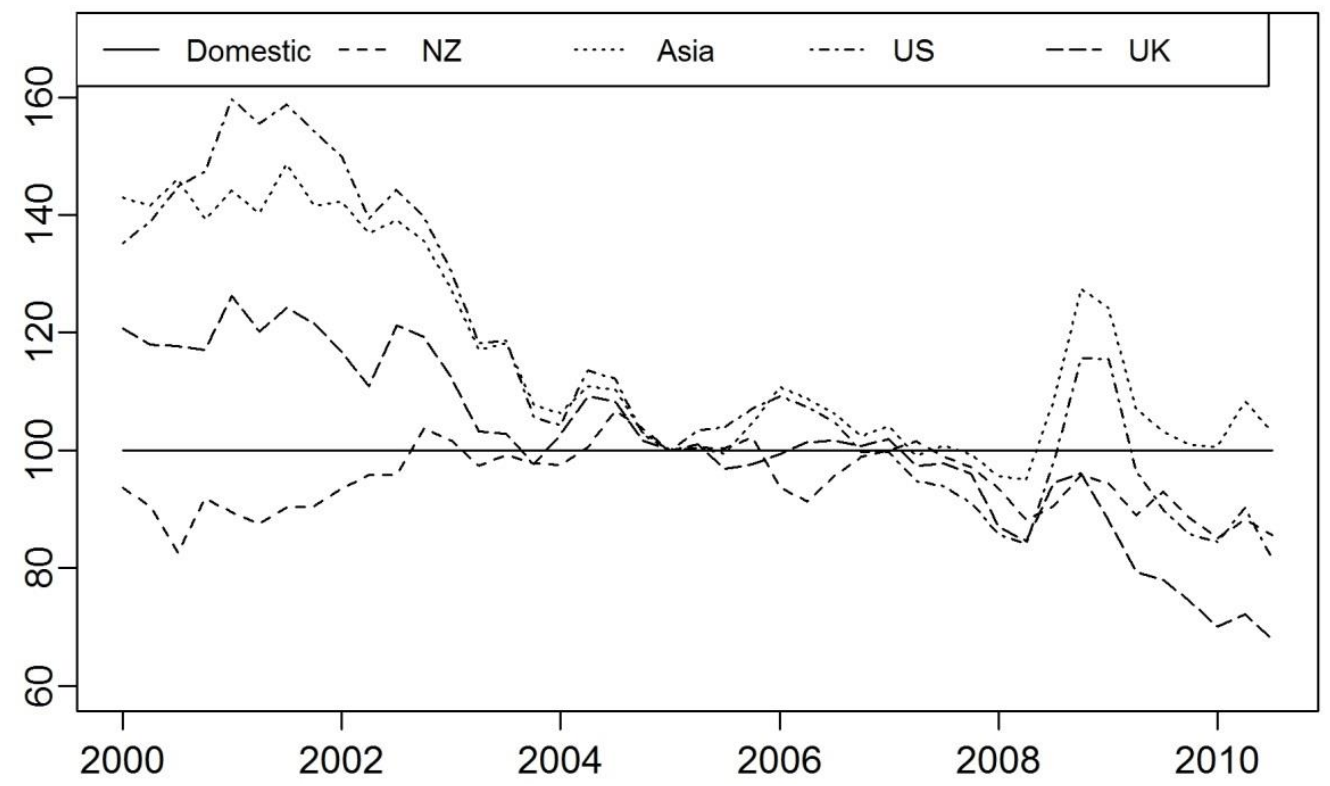

Figure 2. Quarterly Prices as constructed using Equation (4). 


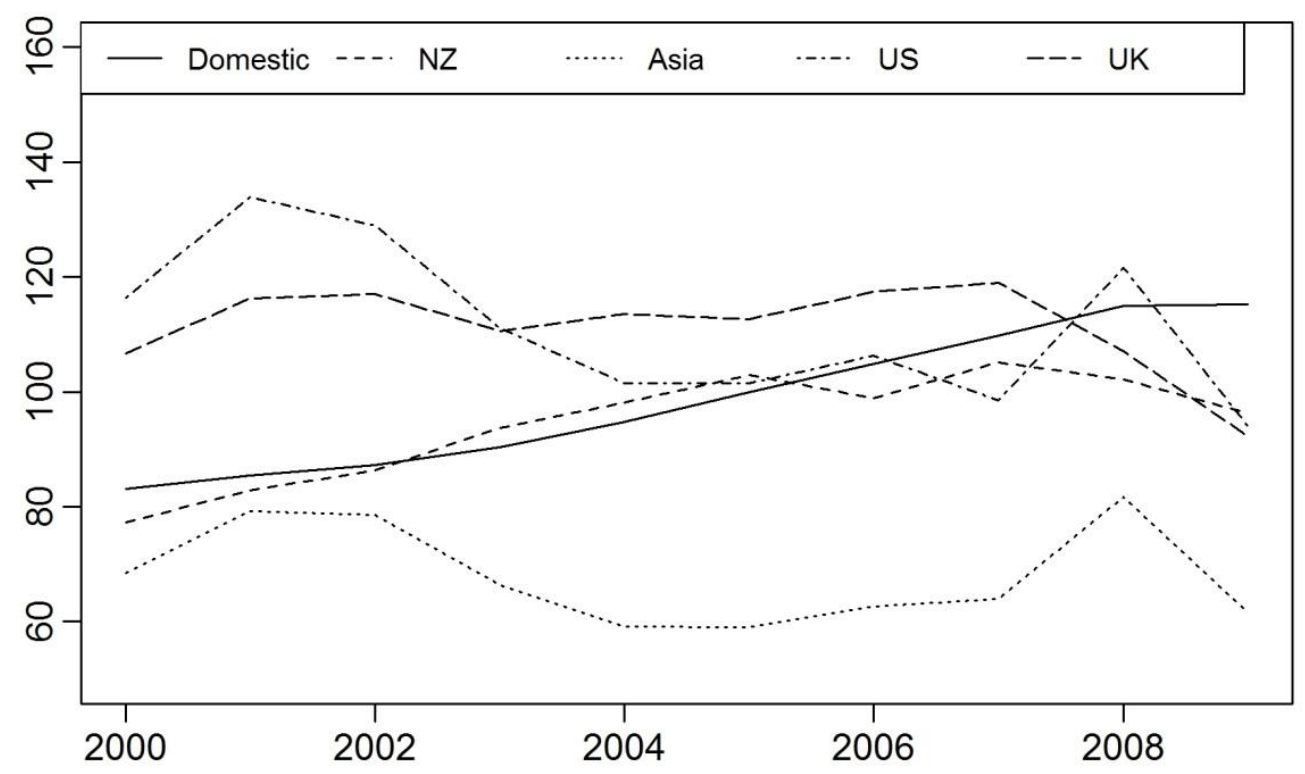

Figure 3. Yearly Modified Relative Price Levels of GDP for Period 2000-2009 


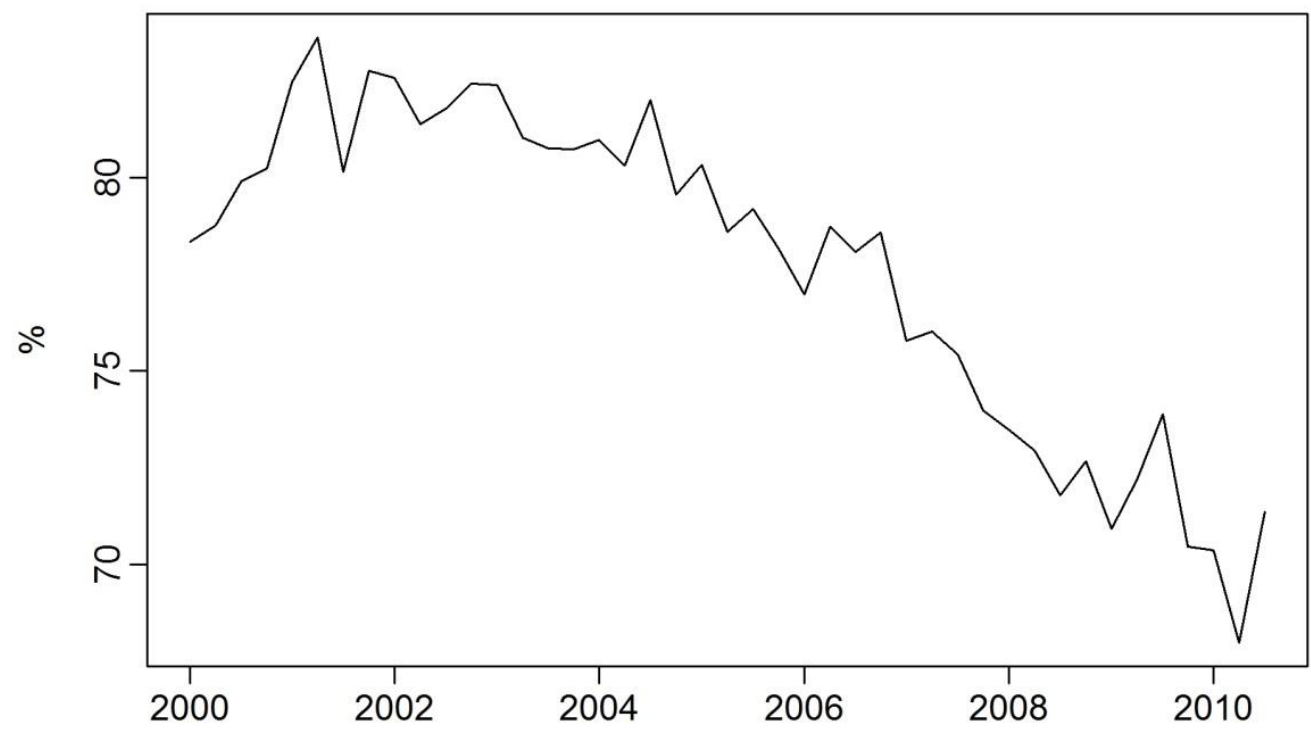

Figure 4: Australian Domestic Tourism Budget Share over the Period 2000Q1-2010Q3 


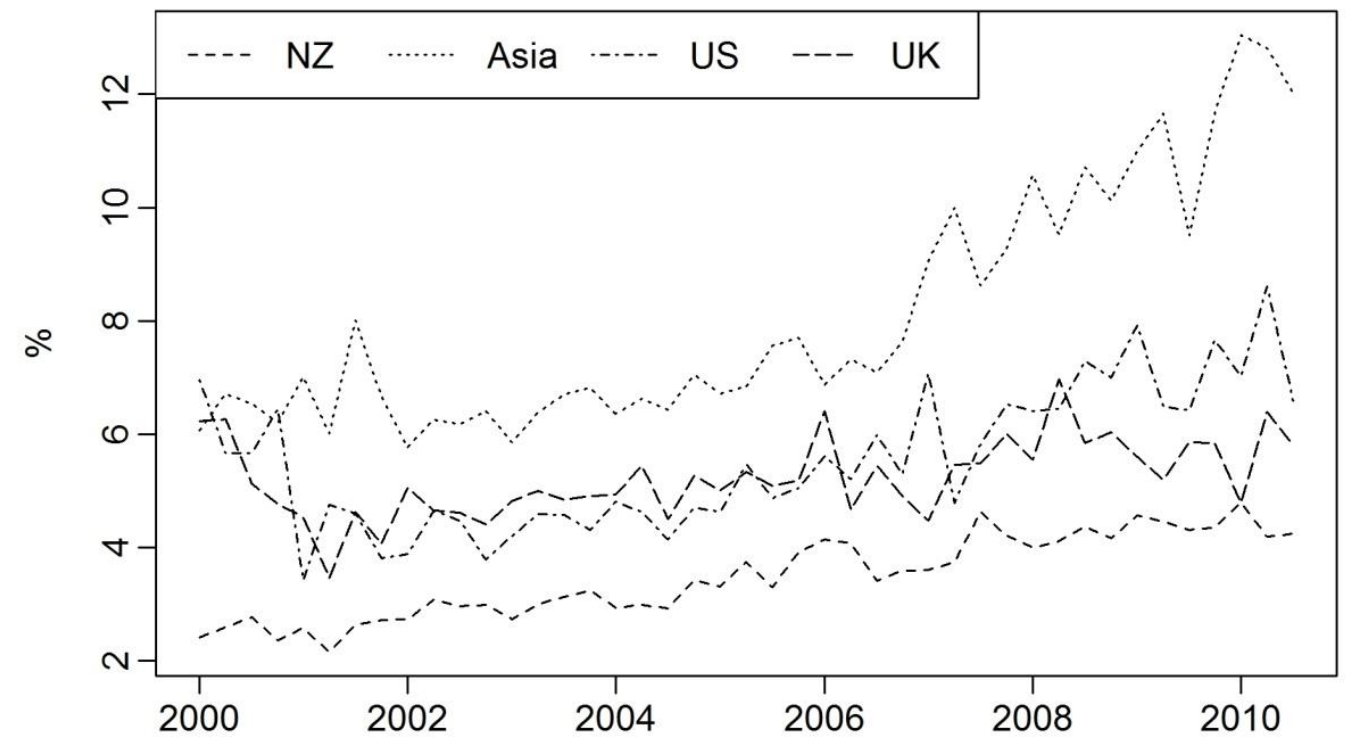

Figure5: Budget Shares of Overseas Destinations over the Period 2000Q1-2010Q3 


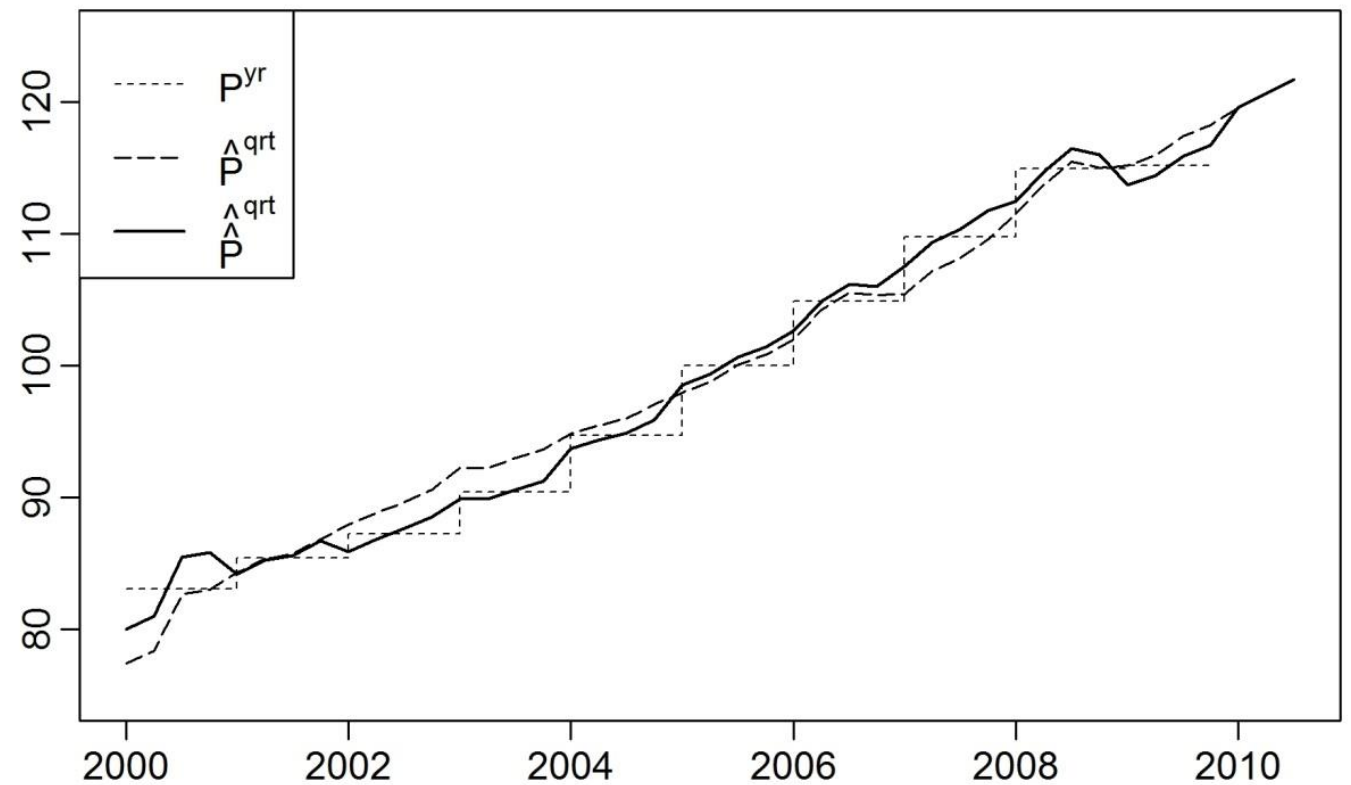

Figure6. Australian Domestic Price Variables

Note: $\boldsymbol{P}^{y r}$ are the observed annual values as specified in Equation (5); $\widehat{\boldsymbol{P}}^{\boldsymbol{q r} t}$ are the estimated quarterly values as specified in Equation (7); $\widehat{\widehat{P}}^{\text {qrt }}$ are the modified estimated quarterly values as specified by Equation (9). 


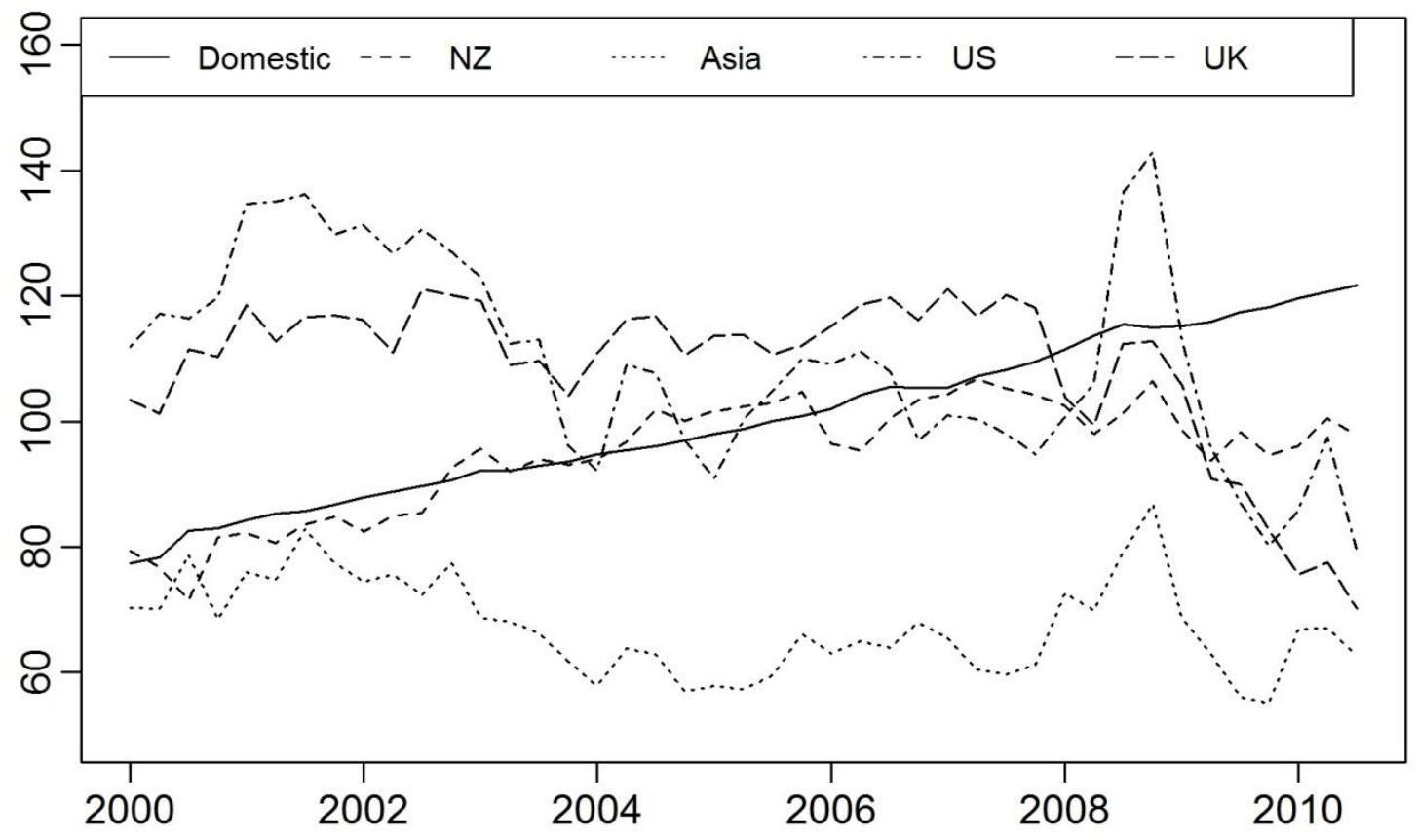

Figure 7. Quarterly Modified Relative Price Levels of GDP 